\title{
Usos e significados do conhecimento histórico em estudos organizacionais: uma (re)leitura do taylorismo sob a perspectiva do poder disciplinar
}

\author{
Uses and meanings of historical knowledge in organizational studies: a (re)reading of \\ Taylorism from the disciplinary power perspective
}

\author{
Eloisio Moulin de Souza ${ }^{1}$ \\ Alessandra Mello da Costa ${ }^{2}$
}

\begin{abstract}
Resumo
O objetivo deste artigo é problematizar - por meio da ampliação dos usos e significados do conhecimento histórico proposta pela perspectiva da nova história e pela genealogia de Michel Foucault - abordagens de estudos organizacionais mais convencionais que assumem como objeto de pesquisa os grandes feitos de grandes homens da história da Administração. Nesse sentido, tem-se: (1) como foco principal de análise uma releitura da versão legitimada do taylorismo como acontecimento histórico diretamente responsável por um conjunto de preceitos e técnicas de racionalização do trabalho; e (2) como argumento central a premissa de que as "subversões" epistemológicas da história renovada e da genealogia possibilitam-nos ler esse acontecimento com outras lentes e identificar a obra de $\mathrm{F}$. W. Taylor como inserida em um conjunto maior de práticas sociais disciplinadoras. Para alcançar esse propósito, o texto está organizado em três partes. Na primeira parte, expõe-se o significado de história para Michel Foucault, em seguida, analisa-se o movimento da história nova e suas convergências com a proposta de conhecimento histórico da genealogia. Por fim, na terceira parte, o taylorismo é repensado e analisado à luz da sociedade disciplinar.
\end{abstract}

Palavras-chave: Nova história. Genealogia. Taylorismo. Conhecimento histórico. Poder disciplinar.

\begin{abstract}
This paper aims to discuss - by expanding the uses and meanings of historical knowledge as proposed from the new history perspective and by Michel Foucault's genealogy - approaches of more conventional organizational studies which take as research object the great deeds of great men in the management history. In this sense, one has: (1) as the main focus of analysis a re-reading of the legitimate version of Taylorism as a historical event directly responsible for a set of precepts and techniques of work rationalization; and (2) as the central argument the premise that epistemological "subversions" of renewed history and genealogy allow us to read this event through other lenses and identify the work of F. W. Taylor as included into a larger set of disciplinary social practices. In order to achieve this purpose, the text is organized in three parts. In the first part, one exposes the meaning of history for Michel Foucault, then, one analyzes the new history movement and its convergences with the historical knowledge proposal of genealogy. Finally, in the third part, Taylorism is rethought and analyzed under the light of disciplinary society.
\end{abstract}

Keywords: New history. Genealogy. Taylorism. Historical knowledge. Disciplinary power.

Artigo submetido em 14 de janeiro de 2013 e aceito para publicação em 08 de março de 2013.

Doutor em Psicologia pela Universidade Federal do Espírito Santo; Professor adjunto do curso de Administração da Universidade Federal do Espírito Santo. Endereço: Avenida Fernando Ferrari, 514, Centro de Ciências Jurídicas e Econômicas, Departamento de Administração, Goiabeiras, CEP 29075-510, Vitória - ES, Brasil. E-mail: eloisiomoulin@gmail.com

2 Professora Assistente do IAG - Pontifícia Universidade Católica do Rio de Janeiro (PUC RIO); Doutora em Administração pela Fundação Getulio Vargas/EBAPE. Endereço: Rua Marquês de São Vicente, 225 - Prédio IAG - Gávea, CEP 22451-900, Rio de Janeiro - RJ. E-mail: alessandra.costa@iag.puc-rio.br 


\section{Introdução}

O objetivo deste artigo é problematizar - por meio da ampliação dos usos e significados do conhecimento histórico proposta pela perspectiva da nova história - abordagens de estudos organizacionais mais convencionais e que assumem como objeto de pesquisa os grandes feitos de grandes homens da história da Administração. Nesse sentido, tem-se como foco principal de análise uma releitura do taylorismo utilizando os princípios genealógicos desenvolvidos por Foucault (1979; 1987; 2003b).

Cabe ressaltar dois pontos nesse caminho. O primeiro refere-se a pensar as possíveis contribuições da perspectiva histórica na área de estudos organizacionais. Tal procedimento não se apresenta como novo e vários pesquisadores, nos últimos anos, têm desenvolvido seus trabalhos dando destaque à potencialidade dessa temática (ALCADIPANI e BERTERO, 2011; ROWLINSON, JACQUES e BOOTH, 2009; ÜSDIKEN e KIESER, 2004; VIZEU, 2010). No entanto, como argumentam esses autores, grande parte dos estudos que incorporam essa perspectiva ainda se concentram na pesquisa histórica acerca da trajetória (muitas vezes de sucesso) de grandes nomes e/ou de grandes empresas.

Um segundo ponto diz respeito à especificidade de (re)pensar o taylorismo a partir de pressupostos históricos. Esse movimento também não é algo novo. A história da gestão (Management History), por exemplo, possui uma ramificação em seu campo de estudo que se concentra em pesquisas focadas em $\mathrm{F}$. W. Taylor e a influência da Administração científica (WREGE e HODGETTS, 2000). Vale ressaltar que este artigo não almeja uma descrição mais detida dos fatores anteriores a Taylor relacionados à organização e sistematização do trabalho. Em uma direção mais crítica e aproximando-se do movimento de uma história renovada, pode-se destacar o fórum de debate em torno do periódico Management \& Organizational History (BOOTH e ROWLINSON, 2006). Fora do âmbito dos estudos organizacionais, como na área de Sociologia, tal movimento também já fazia parte das preocupações centrais da sociologia nova francesa de Georges Friedmann, que incorpora a história e situa o movimento taylorista no movimento processual histórico mais amplo do trabalho industrial (FRIEDMANN e NAVILLE, 1973; FRIEDMANN, 1972).

Dessa forma, a novidade e, talvez, a principal contribuição deste trabalho seja trazer essa discussão para o interior da área de estudos organizacionais e dar a esta um teor mais crítico por meio do arcabouço teórico de Michel Foucault. De modo a alcançar o objetivo proposto, este artigo está organizado em três grandes eixos temáticos: primeiramente, será exposto o significado de história para Michel Foucault, em seguida, será analisado o movimento da história nova e as possíveis aproximações e afastamentos entre esta e a genealogia, e, por fim, será analisado o taylorismo à luz da genealogia foucaultiana e suas relações com a história e a sociedade disciplinar.

\section{O Significado de História em Foucault}

Meu desejo, em todo o caso, era dar a um olhar tão agudo e imparcial uma direção melhor, a direção da efetiva história da moral, prevenindo-o a tempo contra essas hipóteses inglesas que se perdem no azul. Pois é óbvio que uma outra cor deve ser mais importante para um genealogista da moral; o cinza, isto é, a coisa documentada, o efetivamente constatável, o realmente havido, numa palavra, a longa, quase indecifrável escrita hieroglífica do passado moral humano! (NIETZSCHE, 1998, p. 13).

Não é por acaso que iniciamos este tópico com uma citação de Nietzsche (1998), pois o significado da história para Foucault é influenciado pela obra de Nietzsche. Para entender a citação acima, dois adjetivos devem ser destacados: azul e cinza. O que eles significam? Qual é sua relação com o conceito de história na genealogia nietzschiana? 
Cinza é uma cor neutra, que não sobressai diante de outras cores. É uma cor que passa despercebida, ou seja, não serve para evidenciar, salientar e destacar algo. Já o azul é algo "vivo", saltitante aos olhos, evidente, enfim, serve para destacar e evidenciar. Por que, então, apesar da falta de brilho e "vida" do cinza em relação ao azul, Nietzsche (1998) parece valorizar muito mais o cinza do que o azul? Qual seria a relação desse fato com a história, segundo a genealogia?

Ora, se o cinza não salienta, não evidencia e não destaca, de forma análoga, a história, para o genealogista, deve ser vista como sendo algo cinza, pois ela não é constituída e construída por mudanças abruptas, nem por grandes fatos e momentos históricos identificáveis em um instante bem definido do cosmo, como, por exemplo, a Revolução Francesa de 1789, com a Queda da Bastilha, o Maio de 1968 ou a Revolução Russa de 1917. Nem é movida por grandes homens, que seriam os agentes da história. Entender a história como algo construído através de grandes golpes e nomes é atribuir às mudanças históricas a cor azul, ou seja, algo que se possa destacar e atribuir uma relação causa/efeito e uma origem, bem como sua autoria. O azul faz com que o homem comum e anônimo, bem como as diversas práticas sociais cotidianas, não sejam vistos e nem evidenciados como partes importantes constitutivas da história. Assim:

A genealogia exige, portanto, a minúcia do saber, um grande número de materiais acumulados, exige paciência. Ela deve construir seus "monumentos ciclópicos" não a golpes de "grandes erros benfazejos" mas de "pequenas verdades inoperantes estabelecidas por um método severo". Em suma, uma certa obstinação na erudição. A genealogia não se opõe à história como a visão altiva e profunda do filósofo ao olhar de toupeira do cientista: ela se opõe, ao contrário, ao desdobramento meta-histórico das significações ideais e das indefinidas teleologias. Ela se opõe à pesquisa da “origem” (FOUCAULT, 1979, p. 15-16).

Diante dessa citação, fica claro que para a genealogia a história não ocorre por meio de grandes golpes e de mudanças abruptas, nem por fases que se sucederiam em uma relação causa/efeito entre si. Para a genealogia, a história ocorre por meio de discursos, saberes, poderes e práticas cotidianas que, sob um olhar menos meticuloso, passam despercebidos, inofensivos e impotentes. Segundo Rabinow e Dreyfus (1995), o discurso histórico moderno toma a história um progresso que caminha em direção a uma verdade. Os autores evidenciam que Foucault fará um movimento contrário ao discurso histórico moderno ao afirmar que o discurso não é a expressão externa e progressiva de um significado profundo interno, portanto, hermenêutico. Pelo contrário, o discurso revela em sua superfície suas próprias mudanças sistemáticas e suas regras.

Contudo, essa posição de Foucault (2002) não é algo inteiramente novo que emerge em seu momento genealógico. Para Foucault (2002) a arqueologia já coloca em suspensão a ideia de que a sucessão é algo absoluto e um encadeamento necessário e indissociável. Contudo, como Rabinow e Dreyfus (1995) demonstram, enquanto na arqueologia Foucault buscava entender a raridade dos enunciados, a genealogia estabelece uma complementaridade entre a raridade dos enunciados e a formação dos saberes e discursos pelas práticas não discursivas. Para Foucault:

As diferentes emergências que se podem demarcar não são figuras sucessivas de uma mesma significação; são efeitos de substituição, reposição e deslocamento, conquistas disfarçadas, inversões sistemáticas. Se interpretar era colocar lentamente em foco uma significação oculta na origem, apenas a metafísica poderia interpretar o devir da humanidade. Mas se interpretar é se apoderar por violência ou sub-repção, de um sistema de regras que não tem em si significação essencial, e lhe impor uma direção, dobrá-lo a uma nova vontade, fazê-lo entrar em um outro jogo e submetê-lo a novas regras, então, o devir da humanidade é uma série de interpretações. E a genealogia deve ser a sua história: história das morais, dos ideais, dos conceitos metafísicos, história do conceito de liberdade ou da vida ascética, como emergências de interpretações diferentes. Trata-se de fazê-las aparecer como acontecimentos no teatro dos procedimentos (FOUCAULT, 1979, p. 26).

A genealogia é oposta à história tradicional, pois objetiva "assinalar a singularidade dos acontecimentos, fora de toda finalidade monótona” (FOUCAULT, 1971, p. 145). Nesse sentido, a genealogia procura as 
descontinuidades exatamente onde os desenvolvimentos contínuos e o progresso são encontrados, buscando os acontecimentos nos detalhes menores e sutis, ou seja, nas mínimas mudanças. A genealogia se interessa em como os acontecimentos emergem em um espaço estabelecido não por indivíduos, mas por práticas sociais (RABIBOW e DREYFUS, 1995, p. 121). Para “[...] Foucault a tarefa do genealogista é destruir a primazia das origens, das verdades imutáveis. Ele tenta derrubar as doutrinas do desenvolvimento e do progresso” (RABINOW e DREYFUS, 1995, p. 121).

Uma das principais diferenças entre Foucault e Nietzsche apontada por Rabinow e Dreyfus (1995) é que Nietzsche fundamenta as práticas sociais em táticas de atores individuais, enquanto Foucault se afasta dessa perspectiva, afastando, também, o caráter psicológico e não considerando a motivação psicológica dos atores como fonte, mas como resultado de estratégias sem estrategistas. "Em vez de origens, significados escondidos ou intencionalidade explícita, Foucault, o genealogista, vê relações de força funcionando em acontecimentos particulares, movimentos históricos e história” (RABINOW e DREYFUS, 1995, p. 121).

A não busca de origem, seja essa origem vista como algo relacionado aos nomes de grandes homens que teriam mudado a história, aos grandes inventores ou descobridores, bem como aos grandes movimentos revolucionários apontados como motores da história é uma das principais características da genealogia.

Assim, como já dito, para a genealogia, a história é feita de rupturas, descontinuidades. A ideia de que a história é algo contínuo que sempre tende ao progresso, de que existe uma origem a ser descoberta e em cuja origem pode-se encontrar a essência do homem, toda a sua pureza, sua perfeição, enfim, tudo o que prega a metafísica socrático-platônica, é para o genealogista mera ilusão.

A história é necessariamente descontínua, não linear, marcada por rupturas. Rupturas que refletem a luta entre forças que estão sempre se modificando em determinado contexto histórico. Dessa forma, o genealogista procura acompanhar o processo de transformação das relações de poder em vez de fixar definições calcadas em uma busca da verdade, o poder não possui uma natureza, uma essência, uma origem, uma unidade, um objeto, ao contrário, o poder é heterogeneidade em constante transformação (FOUCAULT, 1979).

Sendo o poder relações de força, ele se manifesta em todas as práticas sociais. Assim, o poder passa a ser analisado em sua microfísica e não como algo incorporado e criado pelos aparelhos de Estado. Essa microfísica apresenta o poder como algo periférico e molecular (FOUCAULT, 1979). Dessa forma, os poderes periféricos e moleculares não estão somente no Estado e nem foram confiscados e absorvidos por ele. Não têm sua origem no Estado, nem têm sua origem fora dele, pois o poder não tem origem. O poder manifesta-se no Estado ou em qualquer aparelho central, bem como em toda a periferia da estrutura social (FOUCAULT, 1979). É através de instituições como o Estado, o Judiciário, a escola, a família, a religião, o mercado, a arte etc. que o poder se estabiliza e traça uma linha de força geral. Essa canalização e integração do poder em instituições não caracterizam essas instituições como fontes de poder, nem como sendo sua essência (DELEUZE, 1988). Em suma: o poder não existe, o que existe são relações e práticas sociais nas quais o poder é exercido (FOUCAULT, 1979).

Foucault (1979) salienta que, de certa forma, os mecanismos de poder nunca foram estudados, o que se estudou foram as pessoas e as instituições que detinham o poder, como se elas fossem fontes de poder. "Os poderes se exercem em níveis variados e em pontos diferentes da rede social e neste complexo os micropoderes existem integrados ou não ao Estado" (FOUCAULT, 1979, p. XII). O poder é algo que ninguém pode possuir. Não está nas pessoas, nas instituições, muito menos em um cargo. O poder não é um objeto ou um sujeito, mas uma relação. Portanto, o poder, em seu exercício, vai muito mais longe, passa por canais muito mais sutis, é muito mais ambíguo, porque cada um de nós é, no fundo, titular de certo poder e, por isso, veicula o poder (FOUCAULT, 1979).

Na analítica de poder, Foucault (1987; 1988; 1999; 2003b) preocupa-se em estudar o por que do domínio de um saber, quais condições externas proporcionam o domínio de determinado saber. A genealogia do saber 
deve ser analisada não a partir dos tipos de consciência, percepções ou ideologias, mas das estratégias de poder (FOUCAULT, 1979). "Não há relação de poder sem constituição correlata de um campo de saber, nem saber que não suponha e não constitua ao mesmo tempo relações de poder” (FOUCAULT, 1987, p. 27).

Essa relação poder/saber, em termos genealógicos, é o que possibilita o "acoplamento do conhecimento com as memórias locais, que permite a constituição de um saber histórico das lutas e a utilização deste saber nas táticas atuais” (FOUCAULT, 1979, p. 171). O estudo genealógico consiste em ativar saberes locais, descontínuos, não legitimados e confrontá-los com o saber dominante que pretende purificá-los, ordená-los e classificá-los em nome de um conhecimento verdadeiro. Refere-se a uma insurreição dos saberes contra os efeitos centralizadores do poder que estão ligados às instituições. Trata-se não de dar um fundamento teórico contínuo e sólido a todas as genealogias que estão dispersas, nem de tentar unificá-las, mas de verificar sua emergência e evidenciar o problema que está em jogo nessa oposição, nessa luta, nessa insurreição dos saberes contra a instituição e os efeitos de poder e de saber (FOUCAULT, 1979).

Dessa forma, o poder produz saber e as relações poder/saber não podem ser estudadas a partir de um sujeito que seria livre em relação ao sistema de poder para produzir saber, ao contrário, o sujeito que produz saber também é constituído pelas relações poder/saber de determinada época. "Resumindo, não é a atividade do sujeito de conhecimento que produziria um saber, útil ou arredio ao poder, mas o poder/saber, os processos e as lutas que o atravessam e que o constituem, que determinam as formas e os campos possíveis do conhecimento” (FOUCAULT, 1987, p. 27).

Tendo-se exposto os principais conceitos relacionados à genealogia e à história, algumas questões surgem: Qual é a relação entre a genealogia foucaultiana e a abordagem da nova história? O que é nova história? Quais são as suas principais considerações em relação à análise de um fenômeno dito histórico?

\section{O Movimento Historiográfico da História Nova}

\section{Dos Annales d'Histoire Économique et Sociale aos Annales. Économies, Sociétés, Civilisations}

Pode-se argumentar - no âmbito da história geral da historiografia - que o movimento rumo a um novo tipo de história foi iniciado por dois professores da Universidade de Estrasburgo, Marc Bloch e Lucien Febvre, em 1929, com a publicação do primeiro número da revista Annales d'Histoire Économique et Sociale. Esta adquire importância como centro de convergência do movimento historiográfico de renovação da história e a ideia dessa publicação (posteriormente corroborada pela fundação da VI Seção da École Pratique des Hautes Études) era recusar uma história simplista e superficial abrindo "a disciplina história às temáticas e métodos das outras ciências humanas por meio da formulação de novos problemas, novos métodos e novas abordagens da pesquisa histórica” (CASTRO, 1997).

Assim, o que une Bloch e Febvre é exatamente o posicionamento contrário a uma história dos fatos ("evenementielle"), distante das demais ciências sociais e atrelada aos conceitos positivistas de progresso, ordem, racionalidade. Segundo Burke (2010, p. 13), o momento pode ser entendido com "pequeno, radical e subversivo, conduzindo uma guerra de guerrilhas contra a história tradicional, a história política e a história dos eventos”. Nas palavras de Febvre (2011, p. 84):

Peço aos historiadores, [...] para ir ao trabalho como Claude Bernard, com uma boa hipótese em mente. E que jamais se comportem alegremente como colecionadores de fatos, como antes, quando bancavam os caçadores de livros às margens do Sena. Que nos deem uma História, não uma História automática, mas, sim, problemática. 
Pode-se destacar como principais características desse primeiro momento de uma historiografia renovada: (a) uma narrativa com digressões e remissões; (b) a eventual análise de longos períodos temporais (longa história) ou "períodos históricos mais alargados e estruturas que se modificavam de maneira mais lenta e preguiçosa” (SCHWARCZ, 2001, p. 9); (c) a busca por ampliar e flexibilizar a investigação acadêmica voltando-se aos campos social, econômico e cultural; e (d) uma maior relevância à interpretação de estruturas duradouras (LE GOFF, 2005; NOVAIS e SILVA, 2011).

Em 1945, a revista dos Annales muda de nome e passa a se chamar Annales. Économies, Sociétés, Civilisations. Com sua segunda geração de pesquisadores (que passa a ter seu comitê de direção formado por Fernand Braudel, Georges Friedmann e Charles Morazé), algumas das principais características do primeiro momento são intensificadas. A primeira que merece destaque foi o aumento da tentativa de aproximação com as ciências sociais. A própria alteração do título do periódico que norteia o movimento historiográfico dos Annales (com o desaparecimento do termo História) mostra a importância desse movimento. Essa busca, no entanto, ocorreu com toda sua força na direção do campo econômico. O mundo dessa nova geração é o do pós-Segunda Guerra, cujas temáticas predominantes eram modernização, investimento, crescimento econômico e inflação.

Como desdobramento, o econômico passa a ser o grande articulador do conjunto do universo social e dos quadros de pensamento, relegando a um segundo plano de pesquisa outras possibilidades historiográficas, tais como a história cultural, a história das mentalidades e a psico-história. Ou seja, como mostra Dosse (2003, p. 151), “[...] a história é, nesse momento, mistura de demografia, de curvas econômicas e de análises das relações sociais”.

Uma segunda característica que, intensificada pelos pesquisadores, diz respeito à análise de longos períodos temporais. Fernand Braudel foi o historiador ícone e síntese desse movimento e - voltado ao tipo de pesquisa que prioriza a história serial - aproximava-se de pesquisadores estruturalistas de outras áreas, como Claude Lévi-Strauss. Para Braudel, todas as estruturas estão sujeitas a mudança, mesmo que essas mudanças sejam lentas, o que justifica estudos de longa duração (BURKE, 2010).

Uma terceira característica é o nascimento da história quantitativa, com seus desdobramentos na história dos preços, na história regional, na demografia histórica e na história demográfica. Contudo, para entender as relações entre história nova e genealogia foucaultiana torna-se imprescindível a análise da terceira geração dos Annales.

\section{A história nova: a terceira geração dos Annales}

Denominada terceira geração dos Annales (Em 1969, Fernand Braudel transfere a direção do periódico para André Burguière, Marc Ferro, Jacques Le Goff, Emmanuel Le Roy-Ladurie e Jacques Revel) e dando continuidade ao movimento iniciado por Bloch e Febvre, surge no final dos anos 1960 e início dos anos 1970 a história nova. Esta apresenta-se como uma alternativa à história política tradicional, caracterizada como narrativa dos acontecimentos políticos e militares, apresentada como a história dos grandes feitos de grandes homens e legitimada por uma visão centralizada e institucionalizada do poder (BURKE, 1992). Ao mesmo tempo, deslocam o foco da história econômica para uma história mais voltada ao estudo das mentalidades (DOSSE, 2003).

Como características principais dessa historiografia tradicional - que durante as três primeiras décadas do século XX manteve sua hegemonia quase inalterada - podemos identificar: (a) discurso histórico construído em função de uma epistemologia empirista; (b) análises de curtos períodos temporais; e (c) foco no âmbito político e na atribuição de relevância aos eventos conjunturais e personagens específicos (história baseada em ideias e ações de alguns poucos agentes históricos individuais). Em contraposição à história tradicional, a 
nova história é considerada “a mais recente e dominante tendência da moderna historiografia” (NOVAIS e SILVA, 2011, p. 11) e, de acordo com Le Goff (2005, p. 40), luta contra a história política que

[...] é, por um lado, uma história-narrativa e, por outro, uma história de acontecimentos, uma história fatual, teatro de aparências que mascara o verdadeiro jogo da história, que se desenrola nos bastidores e nas estruturas ocultas em que é preciso ir detectá-lo, analisá-lo, explicá-lo.

Sua proposta é ampliar o domínio historiográfico, assumindo a história como estudo do homem no tempo por meio da redefinição de conceitos fundamentais como documento, fato histórico e tempo. Nesse sentido, a historiografia renovada promove um profundo questionamento tanto da noção de fato histórico (não mais um objeto dado e acabado, mas, sim, construção do historiador) quanto da noção de documento (noção ampliada e não mais considerado algo objetivo e inocente). Ou seja, a história, agora, é escrita no plural, sem a utilização de uma letra maiúscula e sem buscar realizar uma síntese dos seus possíveis múltiplos objetos de pesquisa.

De acordo com Burke (1992), pode-se resumir em seis pontos os principais contrastes entre as duas historiografias. Primeiro, em relação aos objetos da história. No paradigma tradicional, a história diz respeito à política; na história nova, toda atividade humana pode ser objeto da história, como no caso do campo econômico, quase completamente abandonado pela história tradicional.

Segundo, como desdobramento, a história tradicional oferece uma visão de cima, no sentido de que tem sempre se concentrado nos grandes feitos dos grandes homens, estadistas, generais ou eclesiásticos; os novos historiadores estão preocupados com a história vista de baixo, com as opiniões das pessoas comuns e sua experiência de mudança social. A história nova mostra que os grandes acontecimentos são apenas a superfície dos fenômenos, são como “nuvens”:

Por acaso, a história do homem cotidiano também não é tão significativa e dramática quanto a dos grandes homens? [...] A história das maneiras de se vestir, de comer, por acaso não é tão sedutora quanto a das batalhas, das conferências internacionais e das peripécias parlamentares ou eleitorais [...] que só merece ser legada à memória coletiva na medida em que revela ou afeta as estruturas profundas das sociedades e de sua evolução? (LE GOFF, 2005, p. 19).

Terceiro, os historiadores tradicionais pensam na história como sendo essencialmente uma narrativa dos acontecimentos; a nova história está mais preocupada com a análise das estruturas e do tempo longo - da longa duração (o resgate da narrativa pela história nova ocorre apenas no final dos anos 1980, com a quarta geração dos Annales). Segundo Le Goff (2005, p. 62):

[...] a história caminha mais ou menos depressa, porém, as forças profundas da história só atuam e se deixam apreender no tempo longo [...] a história do curto prazo é incapaz de apreender e explicar as permanências e as mudanças. Uma história política que se pauta pelas mudanças de reinados, de governos, não apreende a vida profunda: o aumento da estatura dos humanos, ligado às revoluções da alimentação e da medicina [ou] à mudança das relações com o espaço, decorrente da revolução dos transportes.

Quarto, segundo o paradigma tradicional, a história deveria ser baseada em documentos oficiais escritos; a história nova expõe as limitações desse tipo de documento, examinando maior variedade de evidências, atribuindo menor ênfase às fontes escritas e maior relevância ao uso da história oral, iconografia e vestígios arqueológicos (CARDOSO, 1997). Nesse sentido, “uma estatística, uma curva de preços, uma fotografia, um filme, ou, para um passado mais distante, um pólen fóssil, uma ferramenta, um ex-voto são, para a história nova, documentos de primeira ordem” (LE GOFF, 2005, p. 37). 
Quinto, a história tradicional preocupa-se com as ações dos indivíduos, ao contrário da história nova, que considera relevantes movimentos coletivos e individuais.

E, por último, segundo o paradigma tradicional, a história é objetiva e a tarefa única do historiador é apresentar aos seus leitores os fatos. Hoje em dia, esse ideal é considerado irrealista. A história nova mostra a inevitabilidade da falta de isenção ao olhar sobre o passado, pois "só percebemos o mundo através de uma estrutura de convenções, esquemas e estereótipos, um entrelaçamento que varia de uma cultura para outra" (BURKE, 1992, p. 15).

Os vínculos entre Foucault e os historiadores da história nova são bem conhecidos. Para Burke (2010, p. 133),

[...] no desenvolvimento intelectual de Foucault [...] a nova história francesa desempenhou um papel significativo [...] [e este] caminhou em linhas paralelas às da terceira geração dos Annales [...] [e] da mesma maneira que ela, estava preocupado em ampliar os temas da história.

Nesse sentido, pode-se observar que a genealogia desenvolvida por Foucault (1979; 2003b) ocorreu de forma concomitante ao desenvolvimento da nova história, sendo duplamente influenciada e influenciadora desse movimento, destacando-se na análise genealógica aproximações com a nova história, dentre elas: (a) o combate comum a uma visão linear, contínua e progressiva da história; (b) o abandono da busca dos grandes feitos dos grandes homens (grandes inventores, grandes descobridores) e o interesse por uma história vista de baixo, ou seja, pelas opiniões e experiências de pessoas comuns como agentes da história (trabalhadores, presos, prostitutas, homossexuais, mulheres etc.); (c) a concordância em relação à transformação (e ampliação) da noção de documento, não mais considerado um dado, mas, sim, uma construção social; e (d) a importância atribuída às singularidades e às práticas sociais cotidianas como forma de constituição da história. Para melhor entender e exemplificar os usos e significados dessa possibilidade de conhecimento histórico, optou-se por analisar o taylorismo tendo-se como campo norteador de tal movimento a sociedade disciplinar.

\section{Sociedade Disciplinar: Poderes, Saberes, Corpos e Práticas Sociais}

Se verificarmos os estudos de Foucault sobre as disciplinas, veremos que o poder disciplinar emerge na sociedade ocidental por volta dos séculos XVII e XVIII, por meio de diversas práticas sociais direcionadas ao corpo e ao controle. O poder disciplinar tem por objetivo gerir a vida dos indivíduos e controlá-los em suas relações, em sua aprendizagem, para torná-los dóceis, adestrados e utilizar, assim, uma forma constante de aperfeiçoamento das capacidades humanas, para aproveitá-las ao máximo. O poder passa a ser exercido no corpo social e não sobre o corpo social (FOUCAULT, 1979). Ou seja, as disciplinas têm por principal alvo o corpo, fato que pode ser evidenciado na seguinte citação:

Pois minha hipótese é de que o indivíduo não é o dado sobre o qual se exerce e se abate o poder. O indivíduo, com suas características, sua identidade, fixado a si mesmo, é o produto de uma relação de poder que se exerce sobre corpos, multiplicidades, movimentos, desejos, forças (FOUCAULT, 1979, p. 161-162).

O poder disciplinar é homogeneizante e individualizante. Homogeneizante porque perpassa todo o corpo social para "normalizar" o homem. Torná-lo "normal" significa torná-lo dócil e útil diante das relações de poder de determinado local e de determinada época. Individualizante por se constituir como algo "particular" de cada indivíduo, algo que cada sujeito, objeto desse poder, pensa ser íntimo e pessoal, apesar de não o ser. Portanto, "a disciplina tenta reger a multiplicidade dos homens na medida em que essa multiplicidade pode e deve redundar em corpos individuais que devem ser vigiados, treinados, utilizados, eventualmente punidos" 
(FOUCAULT, 1999, p. 289). As disciplinas dirigem-se ao corpo individual de cada homem, ou seja, a disciplina dirige-se aos campos individuais e os individualiza. Assim, o poder não pode ser explicado apenas por sua função negativa, mas se deve, para o entender, analisar sua eficácia produtiva, sua positividade, pois o indivíduo é uma produção do poder e do saber, tendo como efeito a constituição de sua subjetividade.

Assim, emerge uma sociedade, denominada por Foucault sociedade disciplinar, que tem como característica menos a "defesa geral da sociedade do que o controle e a reforma psicológica e moral das atitudes e do comportamento dos indivíduos" (FOUCAULT, 2003a, p. 85). Instala-se o controle social, a vigilância constante e o exame. A grande máquina de ortopedia social é o Panopticon, modelo de prisão desenvolvido por Jeremy Bentham. Seus princípios serão utilizados nas escolas, nas prisões, nos hospitais, nas fábricas, nos internatos, nos asilos etc. Mas o que seria o Pan-óptico? Como funciona? Qual é o seu objetivo?

É por meio da ideia de Pan-óptico que Foucault (1979; 1987; 2003a) demonstra como age o poder disciplinar. Sua arquitetura propicia que o poder seja exercido de forma anônima e que, ao mesmo tempo, circule por todos. O Pan-óptico é uma técnica utilizada não somente na prisão, mas que foi difundida para as fábricas, as escolas, os hospitais, os exércitos e atua da seguinte forma: cada pessoa deve ficar em seu respectivo lugar e trancado em sua cela, de onde pode ser observado pelo vigia. As paredes laterais não possibilitam seu contato com os demais companheiros. Torna-se visível, mas não se vê quem o vigia. Assim, o indivíduo passa a ser objeto de uma informação e objeto da constituição de um saber. Se os detentos são condenados, com o Pan-óptico diminui-se o poder de resistência por meio de um complô e de más influências mútuas. Se forem pessoas doentes, diminui-se o risco de contágio. Se forem operários, evitam-se os roubos, as uniões em torno de reivindicações comuns, as comunicações e distrações que atrasam a execução do trabalho ou provocam acidentes.

O Pan-óptico quer colocar nos detentos, operários, estudantes, soldados, pacientes, dentre outros, um efeito constante de visibilidade que produz uma consciência que garantirá o funcionamento do poder. No Panóptico, o poder deve ser visível, mas, ao mesmo tempo, inverificável. Visível porque o indivíduo deve sentirse o tempo inteiro observado pela torre central. Inverificável por que o indivíduo não sabe se realmente está sendo observado, mas deve sentir-se observado mesmo que não o esteja sendo. "No Panopticon vai se produzir algo totalmente diferente; não há mais o inquérito, mas vigilância, exame. Não se trata de reconstituir um acontecimento, mas de algo, ou antes, de alguém que se deve vigiar sem interrupção e totalmente" (FOUCAULT, 2003a, p. 88).

O Pan-óptico é o "diagrama de um mecanismo de poder [...]: é na realidade uma figura de tecnologia política que se pode e se deve destacar de qualquer uso específico” (FOUCAULT, 1987, p. 170). Possui múltiplas aplicações: pode ser utilizado para educar os alunos, fiscalizar os trabalhadores para que executem suas tarefas dentro do exigido e não pratiquem a ociosidade no trabalho. O Pan-óptico será utilizado quando se tiver uma multiplicidade e um grande número de indivíduos a quem se quer impor uma tarefa ou um comportamento. Para Foucault (1987, p. 25-26), “o corpo é investido por relações de poder e de dominação; mas em compensação sua constituição como força de trabalho só é possível se ele está preso num sistema de sujeição [...]; o corpo só se torna útil se é ao mesmo tempo corpo produtivo e corpo submisso”. Vejamos em detalhes como o poder disciplinar se dirige ao corpo individual.

O controle, para ser eficaz, deve atuar sobre cada corpo individualmente, não em massa, para assim trabalhálo em todos os seus detalhes. Atuar sobre o corpo de forma contínua para determinar seus movimentos, seus gestos, sua forma e sua velocidade. Não se quer controlar o comportamento, mas a eficácia e economia de seus movimentos. O controle quer tornar o corpo dócil e útil. "Esses métodos que permitem o controle minucioso das operações do corpo, que realizam a sujeição constante de suas forças e lhes impõem uma relação de docilidade-utilidade, são o que se pode chamar as 'disciplinas'” (FOUCAULT, 1987, p. 118). Cria-se uma política voltada à coerção para atingir o corpo, para treiná-lo.

A “invenção” dessa nova anatomia política não deve ser entendida como uma descoberta súbita, mas como uma multiplicidade de processos muitas vezes mínimos, de origens diferentes, de localizações esparsas, que 
se recordam, se repetem ou se imitam, apoiam-se uns sobre os outros, distinguem-se segundo seu campo de aplicação, entram em convergência e esboçam, aos poucos, a fachada de um método geral. Encontramo-los em funcionamento nos colégios, muito cedo; mais tarde, nas escolas primárias; investiram lentamente em direção ao espaço hospitalar; e, em algumas dezenas de anos, reestruturaram a organização militar. Circularam às vezes muito rápido de um ponto a outro (entre o exército e as escolas técnicas ou os colégios e liceus), às vezes lentamente e de maneira mais discreta (militarização insidiosa das grandes oficinas). A cada vez, ou quase, impuseram-se para responder a exigências da conjuntura: aqui, uma inovação industrial; lá, a recrudescência de certas doenças epidêmicas; acolá, a invenção do fuzil ou as vitórias da Prússia (FOUCAULT, 1987).

Uma afirmação genealógica da história. É isso que Foucault (1979; 1987) faz ao explicar a emergência das disciplinas. Apesar de Foucault desenvolver uma pesquisa exaustiva do poder disciplinar nas prisões, o controle de todos os detalhes da vida e do corpo não tem origem apenas na prisão. Como já salientado, o poder disciplinar também ocorre na escola, nos exércitos, nos hospitais, nas fábricas e nas instituições religiosas. Surge em meio a toda uma racionalização que é fruto da modernidade. Leva consigo todo um conjunto de técnicas, todo um corpo de processos e de geração de saber, de descrições, de obtenção de dados e de receitas. E dessas técnicas, nasce o homem do humanismo moderno (FOUCAULT, 1987).

Para aumentar sua eficiência, a disciplina distribui o homem em determinado espaço. Às vezes, constrói muros como técnica para distribuir o indivíduo em um espaço, como ocorre na prisão e nos quartéis; outras vezes, como nos conventos e nas escolas, utiliza o regime de internato ou cria departamentos organizacionais e divide a execução do trabalho em uma linha de montagem. Entretanto, essa nova microfísica do poder vem encoberta, disfarçada por uma nova estratégia: "Pequenas astúcias dotadas de um grande poder de difusão, arranjos sutis, de aparência inocente, mas profundamente suspeitos, dispositivos que obedecem a economias inconfessáveis, ou que procuram coerções sem grandeza” (FOUCAULT, 1987, p. 120).

Assim, com as disciplinas aparecem espaços cada vez mais complexos. Espaços que possibilitam fixar um indivíduo ao mesmo tempo que permitem sua circulação. Um ordenamento dos homens no espaço. Além disso, a disciplina define as relações que o corpo pode ter com o objeto que opera. "Constitui um complexo corpo-arma, corpo-instrumento, corpo-máquina” (FOUCAULT, 1987, p. 130-131). As fábricas utilizam a técnica disciplinar para tirar proveito das multiplicidades humanas, distribuí-las para tirar delas uma maior produtividade:

Nas fábricas que aparecem no fim do século XVIII, o princípio do quadriculamento individualizante se complica. Importa distribuir os indivíduos num espaço onde se possa isolá-los e localizá-los; mas também articular essa distribuição sobre um aparelho de produção que tem suas exigências próprias. É preciso ligar a distribuição dos corpos, a arrumação espacial do aparelho de produção e as diversas formas de atividade na distribuição dos "postos” (FOUCAULT, 1987, p. 124).

O poder disciplinar é um poder que ao invés de negar, proibir, punir quer adestrar os homens, quer produzir um indivíduo eficiente e útil. Ele age sobre a massa e a separa, analisa, classifica, diferencia e individualiza cada homem. O poder disciplinar atinge seu objetivo por meio de simples instrumentos: o olhar hierárquico (vigilância hierárquica), a sanção normalizadora (regras e normas) e o exame. Aliás, vale ressaltar que o trabalho desenvolvido por Weber $(1981 ; 1999)$ sobre uma sociedade racional/legal, que se exprime principalmente por meio de uma lógica burocrática, não é nada mais que a constatação da emergência de uma sociedade disciplinar.

Portanto, vê-se que Taylor (1969), ao desenvolver, no início do século XX, a Administração “científica”, que tem por principal objetivo criar técnicas de racionalização do trabalho, tornando, assim, os corpos dos trabalhadores mais úteis e produtivos por meio de seus estudos de tempos e movimentos, não estaria inventando nada de novo e nem descobrindo nada. Pelo contrário, sua obra, dentro do contexto histórico descrito, é a emergência de toda uma nova forma de poder que se articula estrategicamente como um poder 
disciplinar. Brandão e Guimarães (1999) demonstram que mesmo técnicas e ferramentas utilizadas nos dias de hoje, como a gestão de competências e de desempenho, são técnicas tayloristas de gestão e têm como "essência” medir e classificar o trabalhador para torná-lo mais dócil e produtivo. Nesse sentido, a próxima sessão objetiva problematizar a atribuição da paternidade do controle dos corpos e dos homens nas fábricas a Taylor.

\section{Maternidade é certeza, paternidade é presunção: Taylor não é o "pai" do "taylorismo"}

Como será argumentado a seguir, pode-se afirmar que Taylor (1969) foi apenas um dos nós de uma rede complexa que forma a sociedade disciplinar, ou seja, os princípios disciplinares não foram inventados por Taylor, nem por qualquer outra pessoa, pois já existiam e atuavam de forma histórica e social, sendo esses princípios disciplinares a maternidade do taylorismo. Por isso, afirmamos que Taylor (1969) não foi o pai do taylorismo, sendo este apenas outro nome dado ao que chamamos de disciplinas. Contudo, não fazemos tal afirmação buscando encontrar outro criador, mas para enfatizar que a história é algo cinza e constituído por diversas práticas sociais anônimas.

Uma visão intimista de subjetividade humana não deve ser levada em consideração na análise histórica. O que existe são processos de subjetivação que moldam, desmoldam, enfim, dobram o homem o tempo todo e constroem sua subjetividade. O indivíduo constitui-se através do fluxo de forças que o passam, perpassam, transpassam, ou melhor, são essas forças que constituem o homem e sua subjetividade. Portanto, valores que os homens pensam ser particulares de cada indivíduo são estabelecidos pelas forças que o constituem.

Os próximos parágrafos almejam esclarecer tais afirmações, neles evidenciaremos algumas características da sociedade disciplinar presentes na lógica taylorista, dentre elas destacam-se: (a) busca de uma maior eficiência produtiva; (b) exercício sutil do poder (microfísica do poder); (c) diminuição de resistências; (d) docilização e adestramento dos corpos; (e) olhar hierárquico, sanção normalizadora e exame; e (f) geração de um saber.

Braverman (1987) cita em sua obra diversos trechos de conversas pessoais de Taylor com os operários que trabalhavam na siderúrgica Bethlehem Steel Company, nos Estados Unidos. Alguns desses diálogos chamam a atenção e partes deles serão descritas aqui. A grande preocupação de Taylor era o aumento da produtividade, fato evidente na seguinte afirmação: "Percebemos que esta turma estava carregando em média 12,5 toneladas longas por homem, diariamente. Ficamos surpresos ao descobrir, depois de estudar o assunto, que um carregador de primeira classe devia manejar entre 47 e 48 toneladas por dia [...]” (BRAVERMAN, 1987, p. 96). O interessante é que o próprio Taylor enfatiza que esse processo de aumento de produção deveria ocorrer de forma

[...] que este trabalho fosse feito sem causar rixas entre os homens, sem qualquer conflito com eles, e cuidar em que os homens estivessem mais felizes e contentes quando carregando à nova taxa de 47 toneladas do que quando estivessem carregando ao antigo índice de 12,5 toneladas (BRAVERMAN, 1987, p. 96).

Existe uma forte correlação entre o objetivo de aumento de produção, a busca de sutileza nas ações que envolvem esse processo de aumento produtivo e a tentativa de redução das resistências com toda a lógica emergida entre os séculos XVII e XVIII relacionada à sociedade disciplinar descrita por Foucault (1979; 1987), pois, como dito, o poder disciplinar objetiva controlar os indivíduos em suas relações para aproveitar as capacidades humanas ao máximo, aumentando sua produtividade, além de diminuir a eventual resistência que isso poderia acarretar, ou seja, faz circular uma relação de poder que, para funcionar, deve atuar de forma sutil, que Foucault (1979; 2003b) chamaria de microfísica, no qual os trabalhadores, mesmo trabalhando praticamente quatro vezes mais que o habitual, têm de sentir-se felizes, para evitar complôs e resistências à organização do trabalho. O poder disciplinar tem por objetivo gerir a vida dos indivíduos e 
controlá-los em suas relações, em sua aprendizagem, para torná-los dóceis, adestrados e utilizar, assim, uma forma constante de aperfeiçoamento das capacidades humanas, para aproveitá-las ao máximo.

De forma correlata ao poder disciplinar, a grande preocupação de Taylor (1969) é a gestão dos corpos por meio de tempos e movimentos, ou seja, o corpo ocupa papel central na Administração científica. Taylor (1969, p. 15) afirma que o

[...] objetivo mais importante de ambos, trabalhador e administração, deve ser a formação e aperfeiçoamento do pessoal da empresa, de modo que os homens possam executar em ritmo mais rápido e com maior eficiência os tipos mais elevados de trabalho [...].

O objetivo é evitar movimentos dispendiosos.

Observa-se que o controle do corpo é o principal intento do poder disciplinar. O controle deve trabalhar os corpos em todos os seus detalhes. Atuar sobre o corpo de modo contínuo para determinar seus movimentos, seus gestos, sua forma e sua velocidade, para se obter a eficácia e economia dos movimentos. O controle quer tornar o corpo dócil e útil. São esses métodos "que permitem o controle minucioso das operações do corpo, que realizam a sujeição constante de suas forças e lhes impõem uma relação de docilidade-utilidade, são o que se pode chamar as “disciplinas”” (FOUCAULT, 1987, p. 118).

Para se obter a docilidade/utilidade dos corpos, Taylor (1969) utiliza-se do olhar hierárquico, da sanção normalizadora e do exame. Enfim, cria uma técnica ou um dispositivo de poder que deve vigiar os trabalhadores e puni-los. As bases do controle em Taylor estão na vigilância cerrada, no treinamento dos corpos e nos incentivos financeiros. Entretanto, como reproduzir no imaginário coletivo a punição? Como torná-la transparente para todos? Simplesmente fazendo do operário um objeto de instrução. A fábrica passa a atuar como um local pedagógico. E, por meio dessa pedagogia, o indivíduo será reconstituído e recuperará sua vontade para o trabalho, "recolocá-lo-á por força num sistema de interesses em que o trabalho será mais vantajoso que a preguiça, formará em torno dele uma pequena sociedade reduzida, simplificada e coercitiva [...]: quem quer viver tem que trabalhar" (FOUCAULT, 1987, p. 100). Portanto, uma reconstrução do homo economicus, que automaticamente exclui a utilização de penas muito breves, pois se as penas fossem breves, isso dificultaria a aquisição das técnicas e do gosto pelo trabalho, ou, se fossem definitivas, isso tornaria inútil qualquer aprendizagem. A fábrica torna-se um instrumento não só de punição, mas, principalmente, de disciplina. A vida na fábrica passa a ser dividida em horários rígidos, com uma vigilância ostensiva. Foucault chega a comparar a prisão com a fábrica:

A prisão se pareceria demais com uma fábrica deixando-se os detentos trabalhar em comum. As razões positivas em seguida: o isolamento constitui "um choque terrível”, a partir do qual o condenado, escapando às más influências, pode fazer meia-volta e redescobrir no fundo de sua consciência o bem; o trabalho solitário se tornará então tanto um exercício de conversão quanto de aprendizado; não reformará simplesmente o jogo de interesses próprios ao homo economicus, mas também os imperativos do indivíduo moral (FOUCAULT, 1987, p. 101).

A vigilância passa a ser reforçada. A amplitude do controle é concebida de modo que um capataz tenha sob sua supervisão um número específico de trabalhadores que possa vigiar de forma ininterrupta e constante. Em um trecho do diálogo entre Taylor e Schimidt (operário pelo qual Taylor começa testar suas ideias) descrito na obra de Braverman (1987, p. 97) ilustra bem essa forma de controle:

Bem, se você é um homem valioso, você fará exatamente como esse homem lhe disser amanhã, de manhã à noite. Quando lhe disser para apanhar uma pilha e andar, você apanha e anda, e quando ele lhe disser para sentar-se e descansar, você se senta. Você faz aquilo certo o dia todo. E, o que é mais, nada de parolagem. Agora um homem valioso faz exatamente o que lhe mandam fazer, e nada de conversa. 
A supervisão cerrada tem por principal objetivo combater a "vadiagem", denominada acima por Taylor "parolagem". Aliás, em seus fundamentos da Administração científica, Taylor (1969) deixa claro nos princípios 9 e 10, respectivamente intitulados "Vadiagem no trabalho" e "Causas da vadiagem no trabalho", sua intenção de controlar os corpos para que sejam mais produtivos, dóceis e úteis à organização.

Observa-se que a fábrica também passa a ser local de formação de um saber. Para se modificar as almas dos trabalhadores, a administração da fábrica necessita conhecer o perigo que o operário oferece e classificá-lo (como Taylor fez ao criar a categoria "homem de primeira classe"), fazer anotações, conhecê-lo. Surge todo um saber que tem por objetivo gerir as pessoas, um saber individualizante que não tem como objeto o comportamento diário do trabalhador, para, dessa forma, medir-se o perigo que o operário oferece para a produção. Assim, a fábrica torna-se local de confinamento similar a um reformatório. Quer-se, por meio da fábrica, modificar não somente o corpo, mas, também, a alma do trabalhador, adestrá-lo, torná-lo útil à organização, imputar-lhe as regras estabelecidas por meio da coerção. Nesse sentido, Foucault (1987, p. 106) afirma que:

[...] finalmente, o que se procura reconstruir nessa técnica de correção não é tanto o sujeito de direito, que se encontra preso nos interesses fundamentais do pacto social: é o sujeito obediente, o indivíduo sujeito a hábitos, regras, ordens, uma autoridade que se exerce continuamente sobre ele e em torno dele, e que ele deve deixar funcionar automaticamente nele. Duas maneiras, portanto, bem distintas de reagir à infração: reconstituir o sujeito jurídico do pacto social - ou formar um sujeito de obediência dobrado à forma ao mesmo tempo geral e meticulosa de um poder qualquer.

Contudo, não há no saber descrito por Taylor nenhuma experiência originária, nova, porque o visível e o enunciável estão ligados às relações de poder que eles mesmos atualizam formando estratos. Enfim, em função do exposto, não se pode atribuir a Taylor a origem desses saberes, nem a criação deles, pois manifestam a matriz de uma sociedade disciplinar na qual Taylor está inserido.

\section{Para Além da Conclusão}

O objetivo deste artigo foi propor novos usos do conhecimento histórico, de forma a problematizar perspectivas tradicionais, em particular, a versão legitimada do taylorismo como o responsável direto por um conjunto de preceitos e técnicas de racionalização do trabalho. Pelo contrário, as "subversões" epistemológicas da história renovada e da genealogia de Foucault nos permitem ler esse movimento com outras lentes e identificar que a obra de F. W. Taylor inseria-se em um conjunto maior de práticas sociais disciplinadoras.

Cabe, ainda, ressaltar que, como foi analisado, ao contrário de grande parte dos filósofos, Foucault tinha uma relação muito próxima com a disciplina histórica (e com a terceira geração dos Analles) e utilizou o conhecimento histórico como os historiadores, ou seja, abordava a "questão histórica em si mesma, e jamais como um caso particular de um problema geral [...] sem buscar nela o natural e o sensato" (VEYNE, 2011, p. 33). No entanto, as relações entre Foucault e os historiadores dos Annales não eram construídas apenas por convergências. Pelo contrário, os embates (e debates) teóricos em universidades, colóquios e periódicos eram recorrentes e polêmicos, já que, como filósofo, Foucault levantava questões que muitas vezes não eram tão bem compreendidas e/ou aceitas.

A aproximação intensifica-se, entretanto, a partir do final dos anos 1980, quando o periódico - novamente renomeado como Histoire, Sciences Sociales - passa a ter uma nova direção (Bernard Lepetit e Roger Chartier) e um novo programa de orientação de pesquisa histórica, baseado em uma virada histórica em relação às posições anteriores, tais como: (a) a mobilização da hermenêutica como recurso teórico; (b) o redimensionamento do discurso interdisciplinar; (c) o retorno da dimensão interpretativa da história; e (d) a 
compreensão da sociedade como prática social (DOSSE, 2003). De qualquer forma, influenciando ou sendo influenciada, no que diz respeito ao debate em torno dos usos e significados do conhecimento histórico e das diferentes relações entre poder e política para a compreensão do passado, a nova história e a genealogia tornaram possível "a abertura para concepções novas e variadas a respeito de temas pouco frequentados pela historiografia: os poderes, os saberes enquanto poderes, as instituições supostamente não políticas, as práticas discursivas” (FALCON, 1997, p. 75).

Nesse sentido, poder e política passam ao domínio das representações sociais e de suas conexões com as práticas sociais, adquirindo relevância e prioridade questões acerca do simbólico (simbolismo, formas simbólicas, poder simbólico), das representações sociais ou coletivas, dos imaginários sociais, da memória (ou memórias coletivas), das mentalidades e das práticas discursivas associadas ao poder. É nesse contexto que se considera de suma importância que o taylorismo, bem como as demais abordagens relacionadas à teoria organizacional, sejam entendidas dentro de seu contexto histórico, ou seja, que as disciplinas ministradas sobre teoria organizacional enfatizem o entendimento histórico, suas permanências, singularidades e relações com os mecanismos de poder inerentes a cada época. Como sugestão para futuras pesquisas, seria interessante o desenvolvimento de estudos na área de Administração que utilizem a perspectiva de análise histórica apresentada nas formas contemporâneas de organização do trabalho, formas estas que buscam: (a) romper com o modelo taylorista, como, por exemplo, os modos flexíveis de reestruturação do trabalho; e (b) questionar consensos acerca de feitos fundadores, grandiosos ou quase heroicos de grandes homens da história da Administração.

\section{Referências}

ALCADIPANI, R.; BERTERO, C. O. A Guerra Fria e o ensino do Management no Brasil: o Ponto IV e a Escola de Administração de Empresas de São Paulo da Fundação Getulio Vargas (FGV-EAESP). In: ENCONTRO DE ENSINO E PESQUISA EM ADMINISTRAÇÃO E CONTABILIDADE DA ANPAD, 3., João Pessoa, 2011. Anais... João Pessoa: [s. n.], 2011.

BOOTH, C.; ROWLINSON, M. Management and organizational history: prospects. Management \& Organizational History, v. 1, n. 1, p. 5-30, 2006.

BRANDÃO, H. P.; GUIMARÃES, T. A. Gestão de competências e gestão de desempenho: tecnologias distintas ou instrumentos de um mesmo constructo? In: ENCONTRO NACIONAL DE PÓS-GRADUAÇÃO E PESQUISA EM ADMINISTRAÇÃO, 13., Foz do Iguaçu, 1999. Anais... Foz do Iguaçu, PR: [s. n.], 1999.

BRAVERMAN, H. Trabalho e capital monopolista: a degradação do trabalho no século XX. 3. ed. Rio de Janeiro: Guanabara, 1987.

BURKE, P. Abertura: a nova história, seu passado e seu futuro. In: BURKE, P. (Org.). A escrita da história: novas perspectivas. São Paulo: Unesp, p. 7-38, 1992.

A escola dos Annales: 1929-1989. São Paulo: Unesp, 2010.

CARDOSO, C. F. História e paradigmas rivais. In: CARDOSO, C. F.; VAINFAS, R. Domínios da história: ensaios sobre teoria e metodologia. Rio de Janeiro: Elsevier, p. 1-26, 1997.

CASTRO, H. História social. In: CARDOSO, C. F.; VAINFAS, R. Domínios da história: ensaios sobre teoria e metodologia. Rio de Janeiro: Elsevier, p. 45-60, 1997.

DELEUZE, G. Foucault. Lisboa: Ed. 70, 1988.

DOSSE, F. A história em migalhas. São Paulo: Edusc, 2003.

FALCON, F. História e Poder. In: CARDOSO, C. F.; VAINFAS, R. Domínios da História. Rio de Janeiro: Elsevier, p. 61-90, 1997. 
FEBVRE, L. Contra o vento: manifesto dos novos Annales. In: NOVAIS, F. A.; SILVA, R. F. (Org.). Nova história em perspectiva. São Paulo: Cosac Naify, p.75-85, 2011.

FOUCAULT, M. Nietzsche, la généalogie, l’histoire. In: FOUCAULT, M. Hommage à Jean Hippolite. Paris: P. V. F., p. 145-172, 1971.

. Microfísica do poder. Organização e tradução de Roberto Machado. Rio de Janeiro: Graal, 1979.

. Vigiar e punir: nascimento da prisão. Petrópolis, RJ: Vozes, 1987.

História da sexualidade: a vontade de saber. Rio de Janeiro: Graal, v. 1,1988.

Em defesa da sociedade: curso no Collége de France. São Paulo: Martins Fontes, 1999.

A arqueologia do saber. 6. ed. Rio de Janeiro: Forense Universitária, 2002.

A verdade e as formas jurídicas. Rio de Janeiro: Nau, 2003a.

Estratégia, poder-saber. Rio de Janeiro: Forense Universitária, 2003 b.

FRIEDMANN, G. O trabalho em migalhas. São Paulo: Perspectiva, 1972.

; NAVILLE, P. Tratado de sociologia do trabalho. São Paulo: Cultrix, v. 2, 1973.

LE GOFF, J. A história nova. São Paulo: Martins Fontes, 2005.

NIETZSCHE, F. W. Genealogia da moral: uma polêmica. São Paulo: Companhia das Letras, 1998.

NOVAIS, F. A.; SILVA, R. F. Introdução: para a historiografia da nova história. In: NOVAIS, F. A.; SILVA, R. F. (Org.). Nova história em perspectiva. São Paulo: Cosac Naify, p. 7-70, 2011.

RABINOW, P.; DREYFUS, H. Michel Foucault: uma trajetória filosófica para além do estruturalismo e da hermenêutica. Rio de Janeiro: Forense Universitária, 1995.

ROWLINSON, M.; JACQUES, R.; BOOTH, C. Critical management and organizational history. In: ALVESSON, M.; BRIDGMAN, T.; WILLMOTT, H. (Ed.). The Oxford handbook of critical management studies. Oxford: Oxford University Press, p. 286-304, 2009.

SCHWARCZ, L. M. Prefácio. In: BLOCH, M. Apologia da história ou o ofício do historiador. Rio de Janeiro: Jorge Zahar, p. 7-14, 2001.

TAYLOR, F. W. Princípios de administração científica. 4. ed. São Paulo: Atlas, 1969.

ÜSDIKEN, B.; KIESER, A. Introduction: history in organization studies. Business History, v. 46, n. 3, p. 321-330, 2004.

VEYNE, P. Foucault: seu pensamento, sua pessoa. Rio de Janeiro: Civilização Brasileira, 2011.

VIZEU, F. Potencialidades da análise histórica nos estudos organizacionais brasileiros. Revista de Administração de Empresas, v. 50, n. 1, p. 37- 47, 2010.

WEBER, M. A ética protestante e o espírito do capitalismo. São Paulo: Pioneira/UnB, 1981.

Economia e sociedade: fundamentos da sociologia compreensiva. Brasília, DF: Ed. UnB, v. 2, 1999.

WREGE, C. D.; HODGETTS, R. M. Frederick W. Taylor's 1989 pig iron observations: examining fact, fiction, and lessons for the new millennium. Academy of Management Journal, v. 43, n. 6, p. 1283-1291, 2000. 